\title{
Evaluation of the cytotoxic potential of Annona muricata Linn leaf extract against N2a-neuroblastoma cells
}

\author{
Brindha Durairaj, B. Bala Preedeba \\ Department of Biochemistry, PSG College of Arts and Science, Coimbatore, Tamil Nadu, India
}

\begin{abstract}
Background: Plants are rich in bioactive compounds with various pharmacological properties, and they can be used effectively to treat various diseases. The ability of Annona muricata, preventing progression of cancer cells by initiating programmed cell death, was focused in the present study. Objective: The objectives of this study were to determine the antioxidant and anticancer potential of A. muricata ethanolic extract (AME) of leaves. Materials and Methods: The antioxidant potential of AME was determined by 2,2-diphenylpicrylhydrazyl (DPPH) radical scavenging activity, 2,2'-azinobis(3-ethyl-benzothiozoline)-6-sulfonic acid ammonium salt (ABTS) radical cation scavenging activity, ferric reducing antioxidant power (FRAP) assay, phosphomolybdenum assay, and the cytotoxic potential of AME over N2a cell lines (neuroblastoma cells) was determined using 3-(4,5-dimethylthiazol-2-yl)-2,5-diphenyltetrazolium bromide, lactate dehydrogenase (LDH), intracellular reactive oxygen species (ROS), and measurement of mitochondrial membrane potential (MMP) assay. Results: The 50\% scavenging ability of the extract in DPPH assay was found to be $14 \mu \mathrm{g} / \mathrm{mL}$. The ABTS radical scavenging potential was measured to be $10507.3 \mathrm{mg} / \mathrm{g}$ of extract. The FRAP was found to be $10.38 \mathrm{mM} \mathrm{Fe}(\mathrm{II}) \mathrm{E} /$ $\mathrm{mg}$ extract. The effective phosphomolybdenum reduction was measured at a concentration of $53.33 \mathrm{mg}$ ascorbic acid equivalents/g extract. The in vitro cytotoxicity of AME with escalating concentrations $(5-85 \mu \mathrm{g} / \mathrm{ml})$ was first screened, and it was shown to inhibit $\mathrm{N} 2 \mathrm{a}$ cells with $\mathrm{IC}_{50}$ value of $55 \mu \mathrm{g} / \mathrm{ml}$. A significant increase in cytosolic enzyme LDH confirms the cell membrane damage. The extent of cell damage was confirmed by a significant increase in the level of intracellular ROS and a decrease in MMP. Furthermore, to characterize and identify the major active constituents present in AME, Fourier-transform infrared and gas chromatography-mass spectrometry analysis were carried out. Conclusion: The present results demonstrated that AME could be a promising candidate for developing anticancer agents which helps further to combat neuroblastoma with an effective treatment strategy.
\end{abstract}

Key words: Annona muricata, antioxidant, cytotoxicity, lactate dehydrogenase, neuroblastoma, reactive oxygen species

\section{INTRODUCTION}

$\mathrm{N}$ euroblastoma is the second most common malignant pediatric cancer which affects children under the age of 5 years. $^{[1]}$ In 2013, the American Cancer Society reported that neuroblastoma accounts for $\sim 7 \%$ of childhood cancer and is responsible for $\sim 15 \%$ of deaths in children younger than the age of 15 years. It affects the postganglionic sympathetic nervous system derived from the neural crest cells during embroyonic development. Initially, it develops in the adrenal gland and metastasizes to the liver, bone, bone marrow, lymph nodes, neck, and chest. This tumor comprises of heterogeneous population of cells that differ morphologically, biochemically, and genetically from one another. ${ }^{[2]}$ The available treatment strategy includes the drugs vincristine, cisplatin, Neostar, and nitrogenous mustard compounds, but their extensive use confers for alteration in fundamental cellular processes which leads to multidrug resistance. ${ }^{[3]}$ Even the multimodal therapy such as surgery, radiotherapy in conjugation with chemotherapy, and monoclonal antibodybased immunotherapy for high-risk neuroblastoma remains

\section{Address for correspondence:}

Dr. Brindha Durairaj, Department of Biochemistry, PSG College of Arts and Science, Civil Aerodrome Post, Coimbatore - 641 014, Tamil Nadu, India.

Phone: +91-98422 98546 .

E-mail: publicationbiochemistry@gmail.com

Received: 18-01-2018

Revised: 24-09-2018

Accepted: 15-10-2018 
unsuccessful. ${ }^{[4,5]}$ Hence, there is a need for alternative medicine to combat neuroblastoma. Phytomedicine, as they possess antioxidants and other phytocompounds with greater pharmacological property, offers promising effects for cancer prevention with fewer or no side effects. In recent decades,In recent decades, the extensive research over plant compounds for their therapeutic property has been revealed, especially over the leaves of Annonaceae family (annonaceous acetogenins) for their anticancer properties ${ }^{[6,7]}$ and their promising effects against several diseases on various cell lines. ${ }^{[8-11]}$ Based on these evidence, we sought to investigate the cytotoxic potential of A. muricata ethanolic extract (AME) against N2a cells.

\section{MATERIALS AND METHODS}

\section{Collection and Identification of AME}

The leaves of Annona muricata were collected from Sulur region, Coimbatore, Tamil Nadu. The taxonomic identity of the plant was confirmed and a voucher specimen (No: BSI/SRC/5/23/2015/ Tech.153) has been deposited at the Herbarium of the Botany Department, Tamil Nadu Agricultural College, Coimbatore, Tamil Nadu. The leaves of the plants were made dust free, and the surface of leaves was washed well with tap water and was air dried in the shade for 10-15 days. The dried leaves were weighed, powdered, and used further for extraction process.

\section{Extraction of AME}

The powdered leaves of $A$. muricata were weighed and immersed in $50 \%$ ethanol solvent and placed in $4^{\circ} \mathrm{C}$ for 7 days by occasional shaking (cold maceration). The extract was filtered using Whatman No. 1 filter paper and was concentrated by drying in hot air oven. The powder of $50 \%$ ethanolic extract collected was used for further assays.

\section{Chemicals}

2,2-diphenylpicrylhydrazyl (DPPH), 2,2'-azinobis(3ethyl-benzothiozoline)-6-sulfonic acid ammonium salt (ABTS), trolox (6-hydroxy-2,5,7,8-tetra methylchroman-2carboxylic acid), 2,4,6-Tris (2-pyridyl)-s-triazine (TPTZ), 3-(4,5-dimethylthiazol-2-yl)-2,5-diphenyl tetrazolium bromide (MTT), dimethyl sulfoxide (DMSO), Eagle's minimal essential medium (MEM), and fetal bovine serum (FBS) were obtained from HiMedia Laboratories (Mumbai), Sisco Research Laboratories (Mumbai), Sigma-Aldrich (USA), and Merck (Bengaluru). All the chemicals and solvents used were of analytical reagent grade.

\section{Cell Line}

The neuroblastoma (N2a) cell line was obtained from the National Centre for Cell Science, India. The cells were seeded into plates and flasks in 1:1, MEM supplemented with $10 \%$ FBS, antibiotic, and antimycotic solution (Sigma, St. Louis, MO, USA) in a conditions of $5 \% \mathrm{CO}_{2}$ and $95 \%$ air at $37^{\circ} \mathrm{C}$. The media were changed on alternate days and treated with different concentrations $(5-85 \mu \mathrm{g} / \mathrm{mL})$ of plant extract dissolved in DMSO and water $(1: 9 \mathrm{v} / \mathrm{v})$.

\section{In Vitro Antioxidant Studies}

\section{DPPH radical scavenging activity}

The antioxidant activity of the extract was determined in terms of hydrogen-donating or radical scavenging ability using the stable radical DPPH. ${ }^{[12]}$ Sample with varying concentration was used and the volume was adjusted to $100 \mu \mathrm{L}$ with methanol. About $3 \mathrm{~mL}$ of a $0.1 \mathrm{mM}$ methanolic solution of $\mathrm{DPPH}^{*}$ was added to the aliquots of samples and standards (BHT and rutin) were vortexed well. Negative control was prepared by adding $100 \mu \mathrm{L}$ of methanol in $3 \mathrm{~mL}$ of $0.1 \mathrm{mM}$ methanolic solution DPPH: The tubes were allowed to stand in the dark for $15 \mathrm{~min}$ at room temperature. The absorbance of the sample was measured at $517 \mathrm{~nm}$ against the blank. Radical scavenging activity of the samples was expressed as $\mathrm{IC}_{50}$ which is the concentration of the sample required to inhibit $50 \%$ of $\mathrm{DPPH}^{*}$ concentration.

\section{ABTS radical cation scavenging activity}

The total antioxidant activity (TAA) of the samples was measured by ABTS radical cation decolorization assay. ${ }^{[13]}$ $\mathrm{ABTS}^{\cdot+}$ was produced on the reaction of $7 \mathrm{mM}$ ABTS aqueous solution with $2.4 \mathrm{mM}$ potassium persulfate in the dark for $12-16 \mathrm{~h}$ at the room temperature. Before assay, this solution was diluted with ethanol (about 1:89 v/v) and equilibrated at $30^{\circ} \mathrm{C}$ to produce an absorbance of $0.700 \pm 0.02$ at $734 \mathrm{~nm}$. After the addition of $1 \mathrm{~mL}$ of diluted $\mathrm{ABTS}^{++}$solution to $10 \mu \mathrm{L}$ of plant extract, all the test tubes were vortexed well and incubated in the dark for $30 \mathrm{~min}$ at room temperature. Triplicate determinations were made at each dilution of the standards (BHT and rutin)/plant extracts, and the absorbance was read against the blank at $734 \mathrm{~nm}$. The unit of TAA is defined as the concentration of Trolox having equivalent antioxidant activity expressed as $\mu \mathrm{M} \mathrm{TE} / \mathrm{g}$ of plant extract.

\section{Ferric reducing antioxidant power (FRAP) assay}

The antioxidant capacities of different extracts of samples were estimated. ${ }^{[14]}$ FRAP reagent $(900 \mu \mathrm{L})$, prepared freshly and incubated at $37^{\circ} \mathrm{C}$ for $30 \mathrm{~min}$, was mixed with $90 \mu \mathrm{L}$ of distilled water and $30 \mu \mathrm{L}$ of test sample or blank. The test samples and reagent blank were incubated at $37^{\circ} \mathrm{C}$ for $30 \mathrm{~min}$ in a water bath. The final dilution of the test sample in the reaction mixture was $1 / 34$. The FRAP reagent was prepared by mixing $2.5 \mathrm{~mL}$ of $20 \mathrm{mM}$ TPTZ in $40 \mathrm{mM} \mathrm{HCl}, 2.5 \mathrm{~mL}$ of $20 \mathrm{mM} \mathrm{FeCl}_{3} .6 \mathrm{H}_{2} \mathrm{O}$, and $25 \mathrm{~mL}$ of $0.3 \mathrm{M}$ acetate buffer $(\mathrm{pH}$ 3.6). At the end of incubation, the absorbance readings were taken immediately at $593 \mathrm{~nm}$ against the reagent blank, using a spectrophotometer. Methanolic solutions of known Fe (II) 
concentration, ranging from 100 to $2000 \mu \mathrm{M}\left(\mathrm{FeSO}_{4} \cdot 7 \mathrm{H}_{2} \mathrm{O}\right)$, were used for the preparation of the calibration curve. The parameter equivalent concentration was defined as the concentration of antioxidant having a ferric-TPTZ reducing ability equivalent to that of $1 \mathrm{mM} \mathrm{FeSO}{ }_{4} \cdot 7 \mathrm{H}_{2} \mathrm{O}$. Equivalent concentration was calculated as the concentration of antioxidant giving an absorbance increase in the FRAP assay equivalent to the theoretical absorbance value of a $1 \mathrm{mM}$ concentration of $\mathrm{Fe}$ (II) solution. BHT, rutin, and quercetin were used as standards.

\section{Phosphomolybdenum assay}

The antioxidant activities of extracts were evaluated by the formation of green phosphomolybdenum complex. ${ }^{[15]}$ About $100 \mu \mathrm{L}$ aliquots of extract was added with $3 \mathrm{~mL}$ of reagent solution ( $0.6 \mathrm{M}$ sulfuric acid, $28 \mathrm{mM}$ sodium phosphate, and 4 $\mathrm{mM}$ ammonium molybdate). The test tubes were covered with foil and incubated in a water bath at $95^{\circ} \mathrm{C}$ for $90 \mathrm{~min}$. After the samples had cooled to room temperature, the absorbance of the mixture was measured at $695 \mathrm{~nm}$ against the reagent blank. The results were reported by means of mean value expressed as mg ascorbic acid equivalent (AAE)/g extract. $\mathrm{BHT}$, rutin, and quercetin were used as reference standards.

\section{Characterization of AME Extract}

\section{Fourier-transform infrared (FT-IR) analysis}

FT-IR spectra were obtained from $\mathrm{KBr}$ (potassium bromide) pellets prepared using $1 \mathrm{mg}$ of powdered whole plant. The pellets were analyzed in the absorption mode of FT-IR, and all spectra were recorded from 4000 to $400 \mathrm{~cm}^{-1}$ at a data acquisition rate of $2 \mathrm{~cm}^{-1}$ using a FT-IR spectrophotometer (Shimadzu).

\section{Gas chromatography-mass spectrometry (GC-MS) analysis}

GC-MS analysis was carried out using Clarus 600 GC system equipped with Clarus $600 \mathrm{C}$ mass spectrometer (PerkinElmer precisely, USA). An Elite-5MS fused silica capillary column coated with a 5\% diphenyl $/ 95 \%$ dimethyl polysiloxane stationary phase $(60 \mathrm{~m} \times 0.25 \mathrm{~mm}$, film thickness $0.10 \mathrm{~m}$, PerkinElmer precisely, USA) was used for GC-MS. The injector temperature was kept at $200^{\circ} \mathrm{C}$, whereas the oven temperature was programmed from $70^{\circ} \mathrm{C}$ to $300^{\circ} \mathrm{C}$ for a total run time of $30 \mathrm{~min}$. Helium was used as carrier gas at a flow rate of $1 \mathrm{~mL} / \mathrm{min}$. An appropriate blank was run, from which the solvent delay was fixed to $4 \mathrm{~min}$. The electron ionization mode with ionization energy of $70 \mathrm{eV}$, ion source temperature of $200^{\circ} \mathrm{C}, \mathrm{GC}$ interface temperature of $240^{\circ} \mathrm{C}$, scan interval of $0.2 \mathrm{~s}$, and fragments ranging from 50 to $600 \mathrm{~m} / \mathrm{z}$ were set for the MS analysis. About $1 \mu \mathrm{L}$ of the extract was injected manually in a splitless mode. The mass spectra of the respective peaks obtained in the GC-MS were compared with the mass fragmentation patterns of standards in the Wiley library.

\section{MTT assay}

Cell viability was defined as the ability of cells to metabolically reduce the MTT to a purple formazan dye. Cells were seeded into individual 96-well plates and incubated under the above conditions. After a day of incubation, cells were treated with various concentration of plant extract ranging from 5 to $85 \mu \mathrm{g} / \mathrm{mL}$. To obtain $\mathrm{IC}_{50}$ values, absorbance was measured at $570 \mathrm{~nm}$ in an ELISA multiplate reader and images were taken in Olympus CKX41 microscope equipped with digital camera (E-330). The percentage inhibition of growth was calculated using the formula, $\%$ Cell viability $=100-[100 \times(\mathrm{Ac}-\mathrm{At}) / \mathrm{Ac}] \mathrm{r}$, where At $=$ Absorbance value of test compound and $\mathrm{Ac}=\mathrm{Absorbance}$ value of control.

\section{Lactate dehydrogenase (LDH) assay}

The cytotoxicity was quantified in terms of plasma membrane damage by measuring the amount of LDH released using LDH kit (Agappe-11407002) according to the manufacturer's instructions. LDH activity was measured through the oxidation of lactate to pyruvate with simultaneous reduction of nicotinamide adenine dinucleotide $\left(\mathrm{NAD}^{+}\right)$at a wavelength of $340 \mathrm{~nm}$. The rate of increase in enzyme activity due to the formation of reduced NADH is directly proportional to the LDH activity in the sample. The N2a cells were plated at a density of $5 \times 10^{4}$ cells/well in 24 -well plate for $24 \mathrm{~h}$, and cells were treated with various concentrations of plant extracts $(5-85 \mu \mathrm{g} / \mathrm{mL})$ for different time intervals (3-24 h). The cells were precipitated by centrifugation at $2500 \mathrm{rpm}$ for $5 \mathrm{~min}$ at $4^{\circ} \mathrm{C}$, and the supernatant $(100 \mu \mathrm{L})$ was mixed with $1000 \mu \mathrm{L}$ reaction mixture and the percentage activity was calculated. The total LDH activity was measured by lysis ( $2 \%$ Triton X-100) of untreated cells. The cells were seeded in Petri dishes $\left(1 \times 10^{6}\right.$ cells $)$ and then treated with different concentrations $(5-85 \mu \mathrm{g} / \mathrm{mL})$ of extract for $24 \mathrm{~h}$.

\section{Measurement of intracellular reactive oxygen species (ROS)}

The intracellular ROS was estimated to measure oxidative stress induced by the toxins using oxidation-sensitive dye 2'-7'-dichlorodihydrofluorescein diacetate (DCFH-DA). ${ }^{[16]}$ The assay is based on the principle that the non-fluorescent fluorescin DCFH-DA derivatives will emit fluorescence after being oxidized by the radicals generated by the toxins. The non-ionic, non-polar DCFH-DA crosses cell membranes and is hydrolyzed enzymatically by intracellular esterases to non-fluorescent DCFH-DA which is oxidized to highly fluorescent dichlorofluorescein (DCF) in the presence of ROS. ${ }^{[17]}$ Therefore, the intracellular DCF fluorescence can be used as an index to quantify the overall oxidative stress generated in the cells. The cells were plated at a density of $5 \times 10^{4}$ cells/well in 24 -well plate for $24 \mathrm{~h}$ and the cells were treated with various concentrations of plant extracts $(5-85 \mu \mathrm{g} / \mathrm{mL})$. Cells were then treated with $20 \mu \mathrm{M}$ DCFH-DA for $30 \mathrm{~min}$, and intracellular ROS was measured by fluorimetric detection of DCF oxidation at an excitation 
wavelength of $485 \mathrm{~nm}$ and an emission wavelength of $522 \mathrm{~nm}$. The DCF fluorescence intensity is proportional to the amount of ROS formed intracellularly. The fluorescent intensity percentage was measured using fluorescent microscope (ZEES).

\section{Mitochondrial membrane potential (MMP) assay}

The electrical potential across the inner mitochondrial membrane was measured using the fluorescent dye rhodamine 123 to estimate the mitochondrial membrane integrity. ${ }^{[18]}$ The cells were cultured in 24 well plates and treated as mentioned earlier. After treatment, rhodamine $123(10 \mu \mathrm{g} / \mathrm{ml})$ was added to the cells and incubated for $60 \mathrm{~min}$ at $37^{\circ} \mathrm{C}$. Then, the cells were collected after washing twice with PBS, and the fluorescence was detected at an excitation wavelength of $485 \mathrm{~nm}$ and an emission wavelength of $535 \mathrm{~nm}$ using Hidex plate chameleon $^{\mathrm{TM}} \mathrm{V}$ (Finland).

\section{Statistical Analysis}

The data were analyzed using one-way ANOVA and the data are expressed as the standard mean value. The graph was generated using GraphPad Prism software.

\section{RESULTS}

\section{In Vitro Antioxidant Analysis of A. muricata Leaf Extract}

The analysis of antioxidant potential would help in determining the total reducing capacity of the plant extract.

\section{DPPH Scavenging Activity}

To check the ability of the extracts to stabilize the DPPH radical in-vitro DPPH measurement assay was selected. DPPH was used as a substrate to evaluate the antioxidant activity of natural products from plant and microbial sources. The results are depicted in Figure 1.

Values are mean of triplicate determination $(n=3) \pm$ standard deviation. From Figure 1, it was evident that DPPH scavenging activity was increased with an increase in the concentration of the extract. The $50 \%$ scavenging ability of the extract was found to be at $14 \mu \mathrm{g} / \mathrm{mL}$, and it was found to be higher when compared to the inhibitory concentrations exerted by rutin and BHT standards.

\section{ABTS Assay}

The ABTS assay is based on the inhibition of absorbance of the radical cation $\mathrm{ABTS}^{+}$that has a long characteristic wavelength absorption spectrum. The efficiency of ABTS radical scavenging potential of $A$. muricata leaf extract was

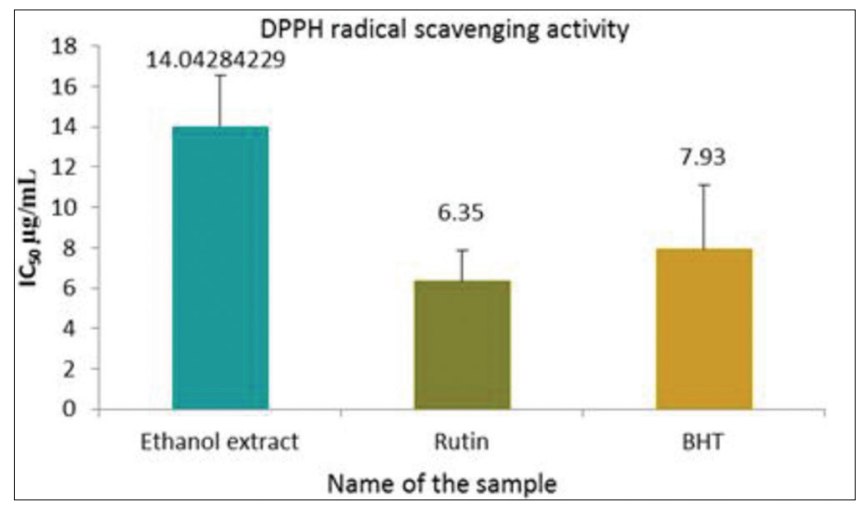

Figure 1:2,2-Diphenylpicrylhydrazyl radical scavenging potential of leaf extract

estimated to identify the total reducing potential of extract, was found to be $10,507.3 \mathrm{mg} / \mathrm{g}$ of extract, and was found to be similar to the reducing potential of the natural antioxidant rutin and greater than that of BHT. The ability of reducing capacity by standard as well as leaf extract is described in Table 1.

\section{FRAP Assay}

The ferric reducing ability of $A$. muricata extracts was estimated based on their ability to reduce TPTZ-Fe (III) complex to TPTZ-Fe (II). The reducing ability of hydroalcoholic extracts by quenching the ions was compared with rutin and quercetin standards, and the potential was found to be $10.38 \mathrm{mM} \mathrm{Fe}(\mathrm{II}) \mathrm{E} / \mathrm{mg}$ extract. Moreover, the concentration of antioxidant in the sample is given in Table 1.

\section{Phosphomolybdenum Assay}

The phosphomolybdenum reduction potential of the leaf extract refers to the ability of the extract to reduce phosphomolybdenum VI to phosphomolybdenum V; this reduction, in turn, reflects the reducing capacity of the hydroalcoholic extract of $A$. muricata. Among the varying concentrations of plant extract, $53.33 \mathrm{mg} \mathrm{AAE} / \mathrm{g}$ extract showed better reduction potential which was comparable with the value of natural antioxidant rutin. Thus, the total antioxidant capacity observed for the extract of A. muricata correlated with its free radical scavenging activity equivalent to that of natural antioxidant ascorbic acid. The reducing potential of extract is represented in Table 1.

\section{FT-IR Analysis of AME}

The functional group in the compound can be identified based on the IR peaks that are obtained based on the percentage transmission. The percentage transmission at particular wavelength determines the functional group of the 
compound. The peaks obtained for the hydroethanolic extract of $A$. muricata are shown in Figure 2.

\section{GC-MS Analysis of AME}

GC-MS was performed to identify the active constituents of AME. The GC-MS chromatogram and spectrum of leaf extract are shown in Figure 3.

\section{MTT Assay}

The cytotoxic effect of $A$.muricata leaf extract with various concentrations ranging from $5-85 \mu \mathrm{g} / \mathrm{mL}$ was observed and it was found to be increase in the concentration of extracts was indirectly proportional to the cell viability, and the result is depicted in Figure 4. After 24 h of extract treatment, all cells exhibited a significant decrease in cell viability even at lower concentration. Moreover, $55 \mu \mathrm{g}$ of the extract decreased the cell viability to $50 \%$. Moreover, this concentration was fixed to be the $\mathrm{IC}_{50}$ concentration and was further confirmed by determining the LDH assay.

\section{LDH Assay}

Cell membrane damage can be confirmed by measuring the leakage of extracellular LDH enzyme, and it was found that the amount of enzyme measured was directly proportional to the treated concentration of extract. The percentage LDH release with varying concentration of extract is shown in Figure 5.

\section{Effect of AME on ROS}

Oxidative stress occurs due to the increase in intracellular ROS level and serves as a major cause for the death of the cell. ${ }^{[19]}$ The rise in free radical creates oxidative stress that leads to the activation of mitochondria-mediated induction of intrinsic apoptotic pathway. The ability of extract in generating ROS is represented in Figure 6.

\section{Determination of MMP}

Loss of MMP is another indicator that indicates the initiation of apoptosis. Hence, the membrane potential was checked by

\begin{tabular}{|c|c|c|c|}
\hline Extracts & $\mathrm{ABTS}^{\circ+}(\mu \mathrm{M}$ TE/g extract) & $\begin{array}{l}\text { FRAP (mM Fe (II) } \\
\text { E/mg extract) }\end{array}$ & $\begin{array}{l}\text { Phosphomolybdenum reduction } \\
\text { (mg AAE/g extract) }\end{array}$ \\
\hline $\begin{array}{l}\text { Hydroalcoholic extract of } \\
\text { A. muricata }\end{array}$ & $10507.3 \pm 139.83$ & $10.387 \pm 1.131$ & $60.66 \pm 7.68$ \\
\hline 7BHT & $8423.95 \pm 96.32$ & - & - \\
\hline Rutin & $9942.69 \pm 109.84$ & $99.19 \pm 1.90$ & $437.19 \pm 6.85$ \\
\hline Quercetin & - & $307.47 \pm 82.70$ & $494.74 \pm 7.95$ \\
\hline
\end{tabular}

Values are mean of triplicate determination ( $n=3) \pm$ standard deviation. TE: Trolox equivalents, AAE: Ascorbic acid equivalents, Fe (II) E: Fe (II) equivalents, ABTS: 2,2'-azinobis (3-ethyl-benzothiozoline)-6-sulfonic acid ammonium salt, FRAP: Ferric reducing antioxidant power, A. muricata: Annona muricata

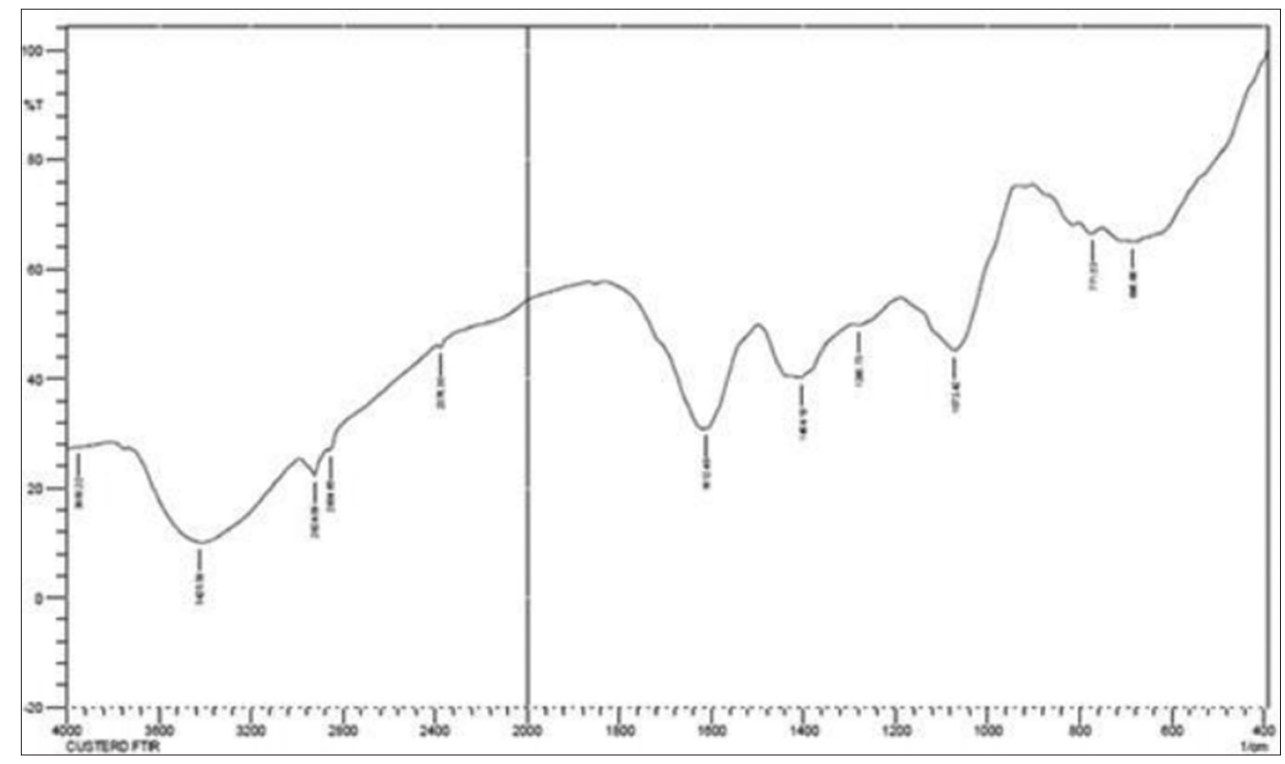

Figure 2: Fourier-transform infrared analysis of Annona muricata leaf extract 


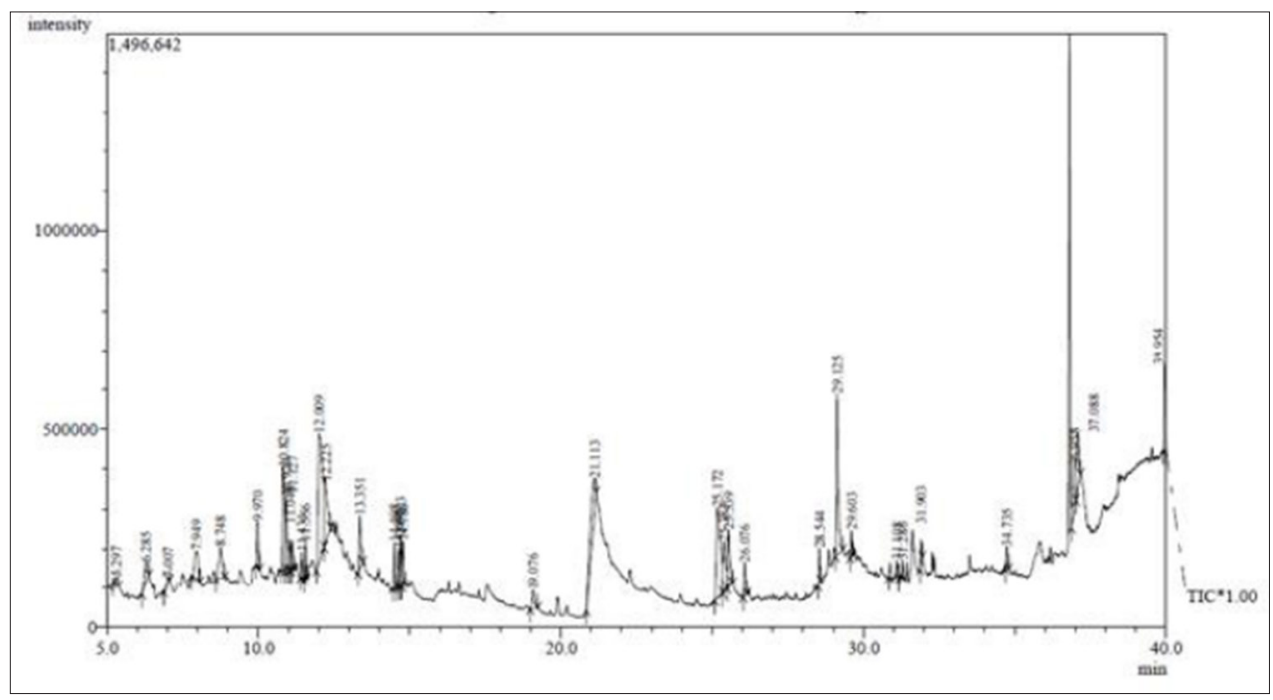

Figure 3: Gas chromatography-mass spectrometry chromatogram of Annona muricata leaf extract

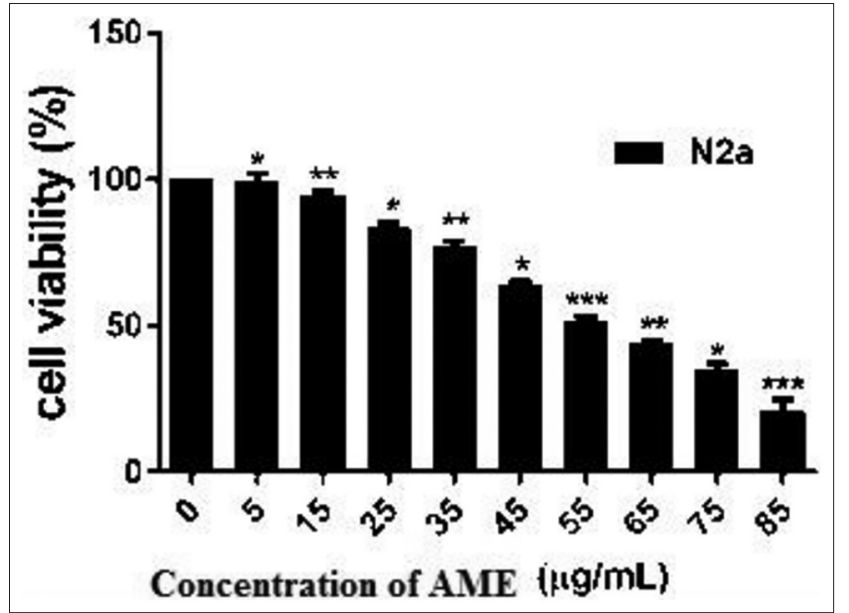

Figure 4: Cytotoxic potential of Annona muricata ethanolic extract against N2a cells. Decrease in cell viability, with an increase in the concentration of plant extract. Results represent the \pm SD of four replicates. ${ }^{*}=0.005 \%$ significant, ${ }^{* *}=0.05 \%$ significance, ${ }^{* * *}=0.1 \%$ significance

treating the cells with varying concentration of plant extract and the concentration of extract, and percentage loss in MMP is shown in Figure 7.

\section{DISCUSSION}

The results of the in vitro antioxidant analysis revealed that the plant possesses compounds that could act as a potent antioxidant, and this property of AME extract makes the platform for the use of this plant for treating any disease. FT-IR analysis reveals the functional groups present in the extract by means of peak ranges, and based on the absorption spectrum, the presence of functional groups in the extract was observed to be the compound containing amino group, compound containing aromatic ring, and other compounds with functional groups such as mono substitution group,

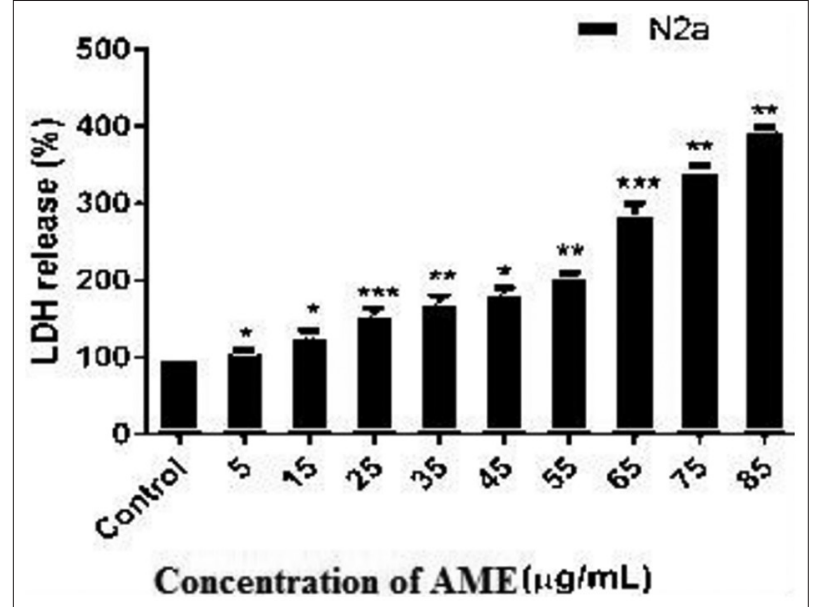

Figure 5: Effect of Annona muricata ethanolic extract on lactate dehydrogenase. Results represent the \pm SD of four replicates. ${ }^{*}=0.005 \%$ significant, ${ }^{* *}=0.05 \%$ significance, ${ }^{* \star *}=0.1 \%$ significance.

carbonyl, and methyl groups. GC-MS using the Wiley library, and based on the retention time of the compounds, the active constituents of the AME were identified which includes dodecane, 4H-Pyran-4-one, 1,5-anhydro-6-deoxyhexo-2,3diulose, methyl triethylsilyl ether, trimethoxyvinylsilane, benzenepropanol, o-chloromethoxybenzene, 7-tetradecene, coumaran,2,3-dihydro-benzofuran, cyclotetradecane, 13-octadecenal, oxirane, and 3-phenylpropanamide. The compounds observed in the study was similar with the results obtained from ethanol extract of $A$. muricata. ${ }^{[20]}$ The cytotoxic assay reveals that the A. muricata leaf extract is highly effective to treat neuroblastoma in dose-dependent manner. The previous study reported the cytotoxic potential of various solvent extracts, and among the studied extracts, ethyl acetate extract of $A$. muricata leaf was found to have very low inhibitory concentration over the lung cancer cells. ${ }^{[11]}$ Results of the present study were in correlation with the earlier works, suggesting that the A. muricata leaf ethanol 


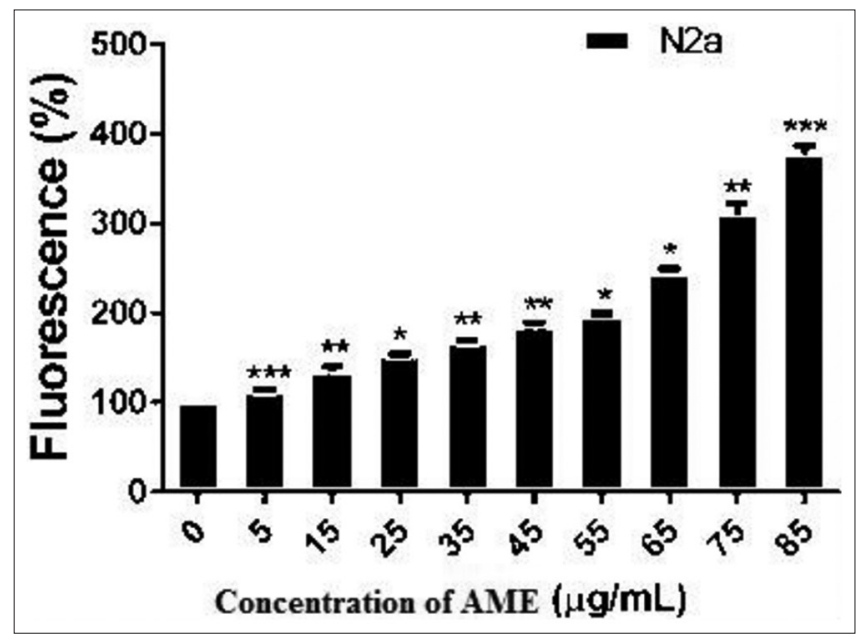

Figure 6: Effect of Annona muricata ethanolic extract on the reactive oxygen species (ROS) generation in N2a cells. Increase in the release of ROS in a dose dependent manner. Results represent the \pm SD of four replicates. * $=0.005 \%$ significant, ${ }^{* *}=0.05 \%$ significance, ${ }^{* * *}=0.1 \%$ significance

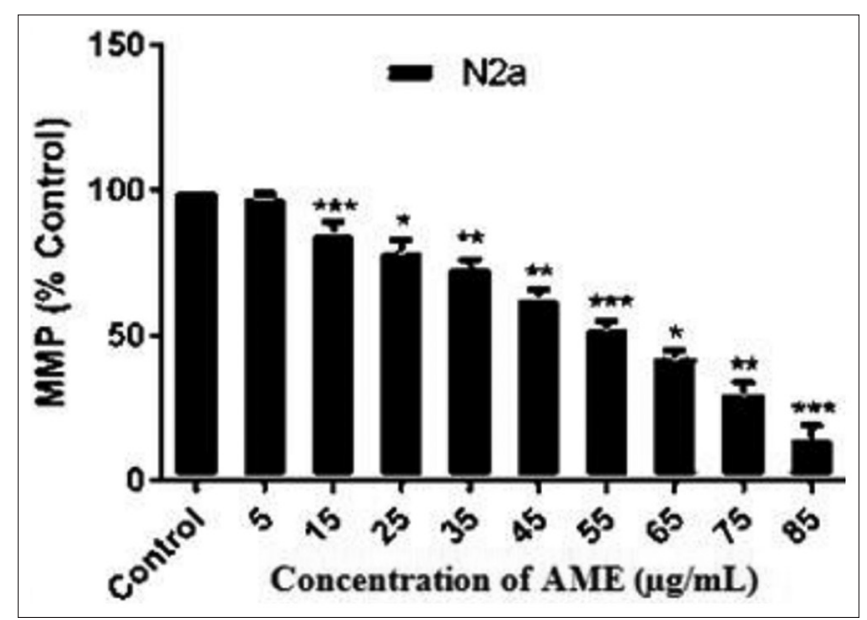

Figure 7: Effect of Annona muricata ethanolic extract over the depletion of mitochondrial membrane potential. The loss in mitochondrial membrane potential with respect to the increasing concentration of plant extracts. Results represents the \pm SD of four replicates. ${ }^{*}=0.005 \%$ significant, ${ }^{* *}=0.05 \%$ significance, ${ }^{* * *}=0.1 \%$ significance

extract can be used as a potential anticancer drug.

The assay revealed that the increase in the leakage of LDH with respect to damage of membrane in a dose-dependent manner, the stable cytosolic enzyme, LDH catalyzes the oxidation of L-lactate to pyruvate. On membrane damage in cells, it is released into the culture medium, suggesting the loss of membrane integrity. ${ }^{[21]}$ Thus, the fixation of inhibitory concentration requires the $\mathrm{LDH}$ test and the result suggests a similar concentration as well, and the $\mathrm{IC}_{50}$ value was found to be $55 \mu \mathrm{g} / \mathrm{ml}$. The present study revealed the potential of extract to induce apoptosis by generating ROS. ${ }^{[11]}$ Hence, the efficiency of extract at the concentration of $55 \mu \mathrm{g} / \mathrm{mL}$ could induce apoptosis in tumor cells. During the process of apoptosis, there will be a great loss in MMP due to the formation of pores, and this determination of MMP would help in serving as an indication for the initiation of apoptosis. When the cells were treated with escalating concentration of AME, the MMP decreased significantly in a dose-dependent manner. The $50 \%$ of loss in membrane potential is known to be the best concentration to act as a cytotoxic substance, and it was found to be as $55 \mu \mathrm{g} / \mathrm{mL}$ for AME which was best noted for the generation of ROS and for decreasing the MMP of the cells.

The chemical profiling of the AME identified the major constituents of the extract which plays a major in anticancer activities such as -4H-Pyran-4-one, benzofuran, 2-amino3-hydroxypyridine, and n-hexadecanoic acid. Further, to determine the membrane damage and to understand the importance of oxidative stress, the ROS measurement was done, which revealed that AME works by inducing intrinsic pathway of apoptosis by generating intracellular ROS in mitochondria, generating pores, and decreasing the MMP of tumor cells. Further, the apoptosis initiation can be confirmed by extending the study for pathway analysis.

\section{CONCLUSION}

The chemical profiling of the AME identified the major constituents of the extract which plays a major in anticancer activities such as -4H-Pyran-4-one, benzofuran, 2-amino3hydroxypyridine, and n-hexadecanoic acid. Further, to determine the membrane damage and to understand the importance of oxidative stress, the ROS measurement was done, which revealed that AME works by inducing intrinsic pathway of apoptosis by generating intracellular ROS in mitochondria, generating pores, and decreasing the MMP of tumor cells. Further, the apoptosis initiation can be confirmed by extending the study for pathway analysis.

\section{ACKNOWLEDGMENT}

The authors are thankful to the director and the scientists of DRDO-BU, Coimbatore, for providing all the facilities required to perform the present study.

\section{REFERENCES}

1. Cheung NK, Dyer MA. Neuroblastoma: Developmental biology, cancer genomics and immunotherapy. Nat Rev Cancer 2013;13:397-411.

2. Kamijo T, Nakagawara A. Molecular and genetic bases of neuroblastoma. Int J Clin Oncol 2012;17:190-5.

3. Alisi A, Cho WC, Locatelli F, Fruci D. Multidrug resistance and cancer stem cells in neuroblastoma and hepatoblastoma. Int J Mol Sci 2013;14:24706-25. 
4. Morgenstern DA, Baruchel S, Irwin MS. Current and future strategies for relapsed neuroblastoma: Challenges on the road to precision therapy. J Pediatr Hematol Oncol 2013;35:337-47.

5. Matthay KK, George RE, Yu AL. Promising therapeutic targets in neuroblastoma. Clin Cancer Res 2012;18:2740-53.

6. Liaw CC, Chang FR, Lin CY, Chou CJ, Chiu HF, $\mathrm{Wu} \mathrm{MJ}$, et al. New cytotoxic monotetrahydrofuran annonaceous acetogenins from Annona muricata. J Nat Prod 2002;65:470-5.

7. Magadula JJ, Innocent E, Otiewo JN. Mosquito larvicidal and cytotoxic activities of 3 Annona species and isolation of active principles.J Med Plants Res 2009;3:674-80.

8. Wang DS, Rizwani GH, Guo H, Ahmed M, Ahmed M, Hassan SZ, et al. Annona squamosa linn: Cytotoxic activity found in leaf extract against human tumor cell lines. Pak J Pharm Sci 2014;27:1559-63.

9. Chang FR, Wu YC. Novel cytotoxic annonaceous acetogenins from Annona muricata. J Nat Prod 2001;64:925-31.

10. Chen Y, Xu SS, Chen JW, Wang Y, Xu HQ, Fan NB, et al. Anti-tumor activity of Annona squamosa seeds extract containing annonaceous acetogenin compounds. J Ethnopharmacol 2012;142:462-6.

11. Moghadamtousi SZ, Kadir HA, Paydar M, Rouhollahi E, Karimian H. Annona Muricata leaves induced apoptosis in A549 cells through mitochondrial-mediated pathway and involvement of NF-kB. BMC Complement Altern Med 2014;14:299.

12. Braca A, De Tommasi N, Di Bari L, Pizza C, Politi M, Morelli I, et al. Antioxidant principles from Bauhinia tarapotensis. J Nat Prod 2001;64:892-5.

13. Re R, Pellegrini N, Proteggente A, Pannala A, Yang M, Rice-Evans C, et al. Antioxidant activity applying an improved ABTS radical cation decolorization assay. Free Radic Biol Med 1999;26:1231-7.
14. Pulido R, Bravo L, Saura-Calixto F. Antioxidant activity of dietary polyphenols as determined by a modified ferric reducing/antioxidant power assay. J Agric Food Chem 2000;48:3396-402.

15. Prieto P, Pineda M, Aguilar M. Spectrophotometric quantitation of antioxidant capacity through the formation of a phosphomolybdenum complex: Specific application to the determination of Vitamin E. Anal Biochem 1999;269:337-41.

16. Wang H, Joseph JA. Quantifying cellular oxidative stress by dichlorofluorescein assay using microplate reader. Free Radic Biol Med 1999;27:612-6.

17. LeBel CP, Ischiropoulos H, Bondy SC. Evaluation of the probe 2', 7'-dichlorofluorescin as an indicator of reactive oxygen species formation and oxidative stress. Chem Res Toxicol 1992;5:227-31.

18. Scaduto RC Jr., Grotyohann LW. Measurement of mitochondrial membrane potential using fluorescent rhodamine derivatives. Biophys J 1999;76:469-77.

19. Adams DJ, Boskovic ZV, Theriault JR, Wang AJ, Stern AM, Wagner BK, et al. Discovery of smallmolecule enhancers of reactive oxygen species that are nontoxic or cause genotype-selective cell death. ACS Chem Biol 2013;8:923-9.

20. Vanitha V, Umadevi KJ, Vijayalakshmi K. Determination of bioactive components of Annona squamosa L leaf by GC-MS analysis. Int J Pharm Sci Drug Res 2011;3:309-12.

21. Chan FK-M, Moriwaki K, De Rosa MJ. Detection of necrosis by release of lactate dehydrogenase activity. In: Snow AL, Lenardo MJ, editors. Immune Homeostasis. New York: Humana Press; 2013. p. 65-70.

Source of Support: The work was carried out with the support of DRDO-BU, Coimbatore and PSG College of Arts and Science, Coimbatore. Conflict of Interest: None declared. 